九州大学学術情報リポジトリ

Kyushu University Institutional Repository

\title{
Effect of Temperature on Lifetime Reproduction of the Egg Parasitoid Ooencyrtus nezarae (Ishii) (Hymenoptera : Encyrtidae)
}

Aung, Kyawt San Dar

Maize and Other Cereal Crops Specialization, Aung Ban, Yezin Agricultural University

Ueno, Takatoshi

Laboratory of Insect Natural Enemies, Division of Biological Control, Department of Applied Genetics and Pest Management, Graduate School of Bioresource and Bioenvironmental Sciences, Kyushu University

\section{Takagi, Masami}

Laboratory of Insect Natural Enemies, Division of Biological Control, Department of Applied Genetics and Pest Management, Graduate School of Bioresource and Bioenvironmental Sciences, Kyushu University

https://doi.org/10.5109/19639

出版情報：九州大学大学院農学研究院紀要. 56 (1)，pp.67-70，2011-02. Faculty of Agriculture， Kyushu University

バージョン :

権利関係 : 


\title{
Effect of Temperature on Lifetime Reproduction of the Egg Parasitoid Ooencyrtus nezarae (Ishii) (Hymenoptera: Encyrtidae)
}

\author{
Kyawt San Dar AUNG ${ }^{1,2}$, Takatoshi UENO ${ }^{2}$
and Masami TAKAGI ${ }^{2 *}$ \\ Laboratory of Insect Natural Enemies, Division of Biological Control, Department of \\ Applied Genetics and Pest Management, Faculty of Agriculture, \\ Kyushu University, Fukuoka 812-8581, Japan \\ (Received October 29, 2010 and accepted November 8, 2010)
}

\begin{abstract}
Parasitoid reproductive biology is one of the central issues in biological control with parasitoids because the successful production of parasitoids is essential to mass-rearing of effective biocontrol agents. Parasitoid's fecundity can be influenced by several physical factors, and temperature is an important factor among them. Ooencyrtus nezarae is a common egg parasitoid attacking several hemipterans including the bean bug Riptortus clavatus, a serious pest of soybean, and is a candidate agent for biological control of soybean pests. In the present study, the lifetime reproduction of $O$. nezarae was examined under different temperature conditions. O. nezarae was able to parasitize host eggs at a wide range of temperatures from 20 to $30^{\circ} \mathrm{C}$, and the highest mean fertility, i.e., the maximum progeny production, was around 75.0 at $25^{\circ} \mathrm{C}$. However, the lifetime production of progeny was largely reduced at 20 and $30^{\circ} \mathrm{C}$ conditions $(33.5$ and 36.0 parasitoid progeny, respectively). Parasitization was also affected by temperature; the lowest parasitism rates occurred at 20 and $30^{\circ} \mathrm{C}$. The parasitism rate at 25 was $20.3 \%$, and was significantly higher than those at other temperature conditions. However, temperatures within the range of 20-30 did not significantly alter the progeny sex ratio and clutch size of $O$. nezarae. The results suggested that $25^{\circ} \mathrm{C}$ was the optimal temperature for efficient mass rearing of $O$. nezarae
\end{abstract}

\section{INTRODUCTION}

Reproduction in parasitoids has been of great interest in biological control because it is a major component of their life history, the important basis for exploring beneficial parasitoids as natural enemies of pests (Price, 1973, 1974; Quicke, 1997; Ueno, 1999a, b; Papaj, 2000). Knowledge of the reproductive capacity of parasitoids is, in particular, fundamental for the evaluation of a biological control agent's potential (Jervis and Kidd, 1996). Reproductive capacity of parasitoids is influenced by physical factors such as temperature, humidity and photoperiod (Denlinger, 1985; Ratte, 1985; Quick, 1997). Progeny production and adult longevity are two of the major factors determining the reproductive capacity of parasitoids (e.g., Andrewartha and Birch, 1954; Syme, 1975, 1977; Harrison et al., 1985; Tingle and Copland, 1988, Ueno, 1998; Aung et al., 2010a, b).

Progeny production by parasitoids can be estimated by examining their fecundity (the total number of laid eggs or number of eggs in the ovary) or with the fertility (the number of viable progeny) (Jervis and Kidd, 1996). However, the fecundity and fertility of parasitoids are variable features that are influenced by a plethora of intrinsic and extrinsic factors (e.g., Ueno, 1999a, c; Papaj, 2000; Ueno and Ueno, 2007; Aung et al., 2010a). The evaluation of a parasitoid's reproductive capacity there-

\footnotetext{
${ }^{1}$ Maize and Other Cereal Crops Specialization, Aung Ban, Yezin Agricultural University

2 Laboratory of Insect Natural Enemies, Division of Biological Control, Department of Applied Genetics and Pest Management, Graduate School of Bioresource and Bioenvironmental Sciences, Kyushu University

* Corresponding author (E-mail: mtakagi@grt.kyushu-u.ac.jp)
}

fore requires a thorough study of the main effects and possible interactions of such factors on parasitoid fecundity and fertility (Jervis and Copland, 1996). In the case of endoparasitoids, however, fecundity is relatively difficult measure because the eggs are laid inside the bodies of hosts. Moreover, fertility is a more reliable criterion to evaluate the reproductive capacity of parasitoids because it represents the net number of progeny after elimination of individuals that fail to complete development (Jervis and Copland, 1996). Thus it is preferable to study fertility rather than fecundity in endoparasitoids upon the evaluation of their reproductive potential.

Ooencyrtus nezarae Ishii (Hymenoptera: Encyrtidae) is a gregarious egg endoparasitoid wasp of several phytophagous Hemiptera including the bean bug, Riptortus clavatus Thunberg (Takasu and Hirose, 1985, 1986; Noda, 1993; Mizutani et al., 1996). It is a good candidate agent for biological control of hemipteran pests of soybean like the bean bug (Takasu and Hirose, 1986; Mizutani et al., 1996). This parasitoid is a synovigenic species, and the females emerge from the host egg without mature eggs (Aung et al., unpublished). Our previous study (Aung et al., 2010a) examining the effect of temperature on estimated fecundity (egg maturation) has shown that a delay of peak for egg maturation occurs with decreasing temperatures and that the maximum egg maturation occurs at $20^{\circ} \mathrm{C}$. However, the effect of temperature on the actual fertility (progeny production) during the lifetime remains unclear. Accordingly, the current study was made to focus on the effect of temperature on progeny production, parasitization rate, clutch size and sex ratio of $O$. nezarae in order to separate the effect of temperature on estimated fecundity (egg maturation) and actual fertility of the parasitoid. 


\section{MATERIALS AND METHODS}

Adult bug Riptortus clavatus, a host of Ooencyrtus nezarae, were collected in the campus of Kyushu University during the summer season. The collected hosts were returned to the laboratory and were reared in plastic cages $(22 \times 16 \times 20 \mathrm{~cm})$ at $25 \pm 1{ }^{\circ} \mathrm{C}$ under a $16 \mathrm{~L}: 8 \mathrm{D}$ photoregime. The bugs were provided with soybean seeds, seedlings and water. Jute strings were also provided for ovipositional sites. Host eggs were collected everyday in order to obtain hosts of the same age class and were kept at $25 \pm 0.5^{\circ} \mathrm{C}$ until use.

Stocks of Ooencyrtus nezarae were obtained from the laboratory cultures maintained at Bioresource and Management Laboratory, Kyushu University. O. nezarae was reared with eggs of the bean bug, and the culture of the parasitoid was maintained as described by Aung et al. (2010b). One pair of adult O. nezarae was taken from the culture and was put into a test glass tube ( $1.5 \mathrm{~cm}$ diameter and $10.5 \mathrm{~cm}$ long) with one $R$. clavatus egg (1-day-old), which was glued on filter paper. The tube was kept at $25 \pm 0.5{ }^{\circ} \mathrm{C}$ under $16 \mathrm{~L}: 8 \mathrm{D}$ for one day for parasitization. After parasitisation, host eggs were singly placed in glass tubes, and were reared until parasitoid emergence. The parasitoids emerged from one host with a ratio of 1 male: 3 females were used for the experiment.

On the day of emergence, each pair of newly emerged parasitoids was put into a test tube that contained 5 host eggs and a droplet of honey. Then, the test tubes containing a pair of parasitoids with hosts were placed at one of the following five different temperature conditions $\left(20,22.5,25,27.5\right.$ or $\left.30^{\circ} \mathrm{C}\right)$. Five young hosts were provided every day, and honey was exchanged once every three days until the female parasitoids died. Thus, the lifetime reproduction of the female $O$. nezarae was examined.

Host eggs were collected from the tubes and were reared as mentioned above. The numbers of emerged progeny and parasitized hosts, and progeny sex ratio were recorded. Twenty females were used for each temperature treatment.

\section{RESULTS AND DISCUSSION}

Ooencyrtus nezarae was able to parasitize host eggs at all temperatures ranging between 20 to $30^{\circ} \mathrm{C}$. However, the progeny production was reduced at low and high temperature conditions (Table 1). The number of progeny differed significantly among temperature groups $(p<0.01)$, indicating that temperature had a significant effect on the fertility of $O$. nezarae. The highest mean fertility, i.e., the maximum progeny production, was observed at $25^{\circ} \mathrm{C}$ (Table 1). Also, parasitization was affected by temperature; parasitism rates (= the number of host eggs parasitized per 5 host eggs) were low at 20 and $30^{\circ} \mathrm{C}$ (Fig. 1). The maximum number of parasitized host eggs was $20.3 \pm 6.6$ at $25^{\circ} \mathrm{C}$, and was significantly higher than those at other temperatures $(\mathrm{p}<0.01)$ (Fig. 1). However, temperature had no significant effects on progeny sex ratio and clutch size $(\mathrm{p}>0.05)$ (Table 1).
Table 1. Effect of temperature on lifetime reproduction of $O$. nezarae

\begin{tabular}{cccc}
\hline Temperature & $\begin{array}{c}\text { No. of progeny } \\
(\text { mean } \pm \text { SD) }\end{array}$ & Clutch size & sex ratio \\
\hline $20^{\circ} \mathrm{C}$ & $33.5 \pm 6.9 \mathrm{a}$ & $4.5 \mathrm{a}$ & $21 \mathrm{a}$ \\
$22.5^{\circ} \mathrm{C}$ & $47.0 \pm 7.3 \mathrm{~b}$ & $4.2 \mathrm{a}$ & $20.5 \mathrm{a}$ \\
$25^{\circ} \mathrm{C}$ & $75.0 \pm 20.3 \mathrm{c}$ & $4.0 \mathrm{a}$ & $20 \mathrm{a}$ \\
$27.5^{\circ} \mathrm{C}$ & $54.0 \pm 12.8 \mathrm{~b}$ & $4.4 \mathrm{a}$ & $21 \mathrm{a}$ \\
$30^{\circ} \mathrm{C}$ & $36.0 \pm 6.6 \mathrm{a}$ & $4.6 \mathrm{a}$ & $19.5 \mathrm{a}$ \\
\hline
\end{tabular}

Mean values followed by the different letters within a column are significantly different at $\mathrm{p}<0.05$ by Tukey-Kramer HSD test.

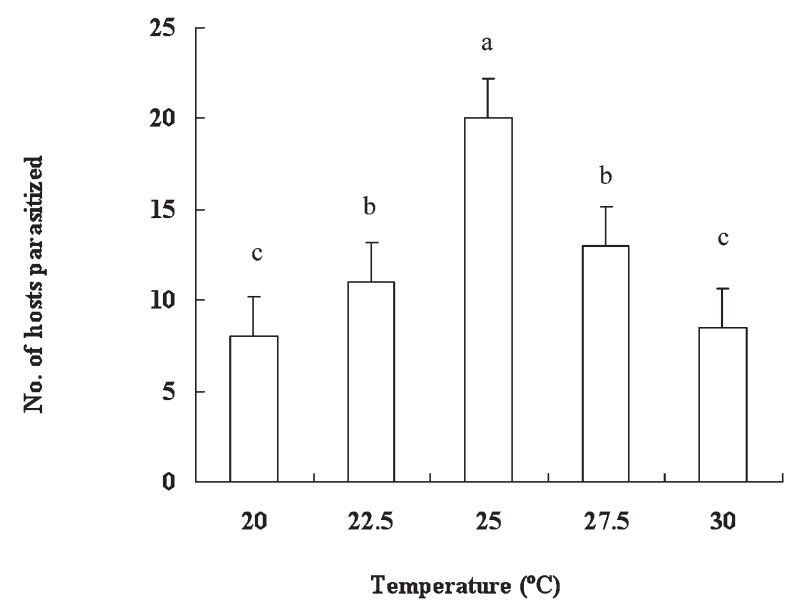

Fig. 1. Mean $( \pm S E)$ number of hosts parasitized during the lifetime of $O$. nezarae reared at different temperatures. The bars capped with different letters differed significantly ( $\mathrm{p}<0.01$, Tukey-Kramer HSD test).

Temperature is one of the most important environmental factors influencing physiology and behavior of insects including parasitoids (Ratte, 1985). A common pattern for the relationship between temperature and parasitoid fertility is that lower fertility is observed at extreme temperatures with higher fertility at moderate temperatures (Force and Messenger, 1964; van Lenteren et al., 1987). Thus, the general presumption is that parasitoid cannot mature their eggs or are unable to oviposit outside a range of tolerable temperatures (Force and Messenger, 1964; Greenfield and Karandinos, 1976).

Many studies have shown that rising temperature reduces longevity and fecundity of parasitoids (Sagarra et al., 2000; Matadha et al., 2004) or the fecundity peaks at medium temperatures (Seal et al., 2002; Agboka et al., 2004; Foerster and Butnariu, 2004; Matadha et al., 2004). The current study is in line with the previous findings for other parasitoids, and the maximum fertility in $O$. nezarae occurs at the moderate temperature, $25^{\circ} \mathrm{C}$. Although our previous finding showed that the maximum egg maturation (estimated fecundity) occurred at $20^{\circ} \mathrm{C}$, the current results revealed the actual fertility, i.e., the highest progeny production, occurs at $25^{\circ} \mathrm{C}$. This may be due to low oviposition activity, which occurs at 
the outside range of tolerable temperatures (Force and Messenger, 1964; Greenfield and Karandinos, 1976). Alternatively, long-term maintenance of the mature eggs may be affected at lower temperatures. At least, the reduced fertility in $O$. nezarae would be due to failure of oviposition of all mature eggs at low temperatures. In any case, our study indicates that $25^{\circ} \mathrm{C}$ is the optimal temperature for maximizing the mass-rearing efficiency of O. nezarae.

The number of mature eggs in the ovary (egg load) can influence many aspects of parasitoid biology and ecology, such as foraging behavior, searching efficiency and motivation to oviposit (Collier et al., 1994; Collier, 1995; Heimpel and Rosenheim, 1998; Ueno, 1999a), which should in turn influence parasitoid and host population processes. Revealing the life history of parasitoids has been the primary approach to evaluate their importance and effectiveness as natural enemies against insect pests (Jervis and Kidd, 1996; Hawkins and Cornell, 1999). However, environmental factors, e.g., temperature, can limit the effect of egg load on parasitoid behavior and ecology; our study suggests the highest fecundity (egg load) in $O$. nezarae at $20^{\circ} \mathrm{C}$ conditions does not necessarily lead to the highest realized progeny production, i.e., fertility. Thus, it is important to evaluate the interactions among environmental factors, physiology and behavior of parasitoids when we assess the reproductive potential of parasitoids in biological control programs.

\section{ACKNOWLEDGEMENT}

We thank Ministry of Education, Culture, Sports, Science \& Technology (MEXT), Japan and Kyushu University foundation for supporting research and academic study.

\section{REFERENCES}

Agboka, K., A. K. Tounou, R. Al-Moaalem, H. M. Poehling, K. Raupach and C. Borgemeister 2004 Life-table study of Anagrus atomus, an egg parasitoid of the green leafhopper Empoasca decipiens, at four different temperatures. Biol. Cont., 49: 261-275

Andrewartha, H. G. and L. C. Birch 1954 The Distribution and Abundance of Animals. The University of Chicago Press, Chicago

Aung, K. S. D., K. Takasu, T. Ueno and M. Takagi 2010a Effect of temperature on egg maturation and longevity of the egg parasitoids Ooencyrtus nezarae (Ishii) (Hymenoptera: Encyrtidae). J. Fac. Agric., Kyushu Univ., 55: 87-89

Aung, K. S. D, M. Takagi and T. Ueno 2010b Influence of food on the longevity and egg maturation of the egg parasitoid Ooencyrtus nezarae (Hymenoptera: Encyrtidae). J. Fac. Agric., Kyushu Univ., 55: 79-81

Collier, T. R., W. W. Murdoch and R. M. Nisbet 1994 Egg load and the decision to host feed in the parasitoid Aphytis melinus. J. Anim. Ecol., 63: 299-306

Collier, T. R. 1995 Host-feeding, egg maturation, resorption, and longevity in the parasitoid Aphytis melinus (Hymenoptera: Aphelinidae). Ann. Entomol. Soc. Am., 88: 206-214

Denlinger, D. L. 1985 Hormonal control of diapause. In "Comprehensive Insect Physiology, Biochemistry and Pharmacology", ed. by G. A. Kerkut and L. I. Gilbert, Pergammon Press, Oxford, 8: 353-412
Foerster, L. A. and A. R. Butnariu 2004 Development, reproduction, and longevity of Telenomus cyamophylax, egg parasitoid of the velvet bean caterpillar Anticarsia gemmatalis, in relation to temperature. Biol. Cont., 29: 1-4

Force, D. C. and P. S. Messenger 1964 Fecundity, reproductive rates, and innate capacity for increase of three parasites of Therioaphis maculata (Buckton). Ecology, 45: 706-715

Greenfield, M. D. and M. G. Karandinos 1976 Fecundity and longevity of Synathedon pictipes under constant and fluctuating temperatures. Environ. Entomol., 5: 883-887

Harrison, W. W., E. G. King and J. D. Ouzts 1985 Development of Trichogramma exiguum and T. pretiosum at five temperature regimes. Environ. Entomol., 14: 118-121

Hawkins, B. A. and H. Cornell 1999 Theoretical Approaches to Biological Control. Cambridge University Press, Cambridge

Heimpel, G. E. and J. A. Rosenheim 1998 Egg limitation in parasitoids: A review of the evidence and a case study. Biol. Cont., 11: 160-168

Jervis, M. A. and M. J. W. Copland 1996 The life cycle. In "Insect Natural Enemies -Practical Approaches to Their Study and Evaluation", Chapman \& Hall, London, pp. 63-161

Jervis, M. A. and N. A. C. Kidd 1996 Insect Natural Enemies: Practical Approaches to their Study and Evaluation. Chapman \& Hall, London

Matadha, D., G. C. Hamilton, and J. H. Lashomb 2004 Effect of temperature on development, fecundity, and life table parameters of Encarsia citrina Craw (Hymenoptera: Aphelinidae), a parasitoid of euonymus scale, Unaspis euonymi (Comstock), and Quadraspidiotus perniciosus (Comstock) (Homoptera: Diaspididae). Environ. Entomol., 33: 1185-1191

Mizutani, N., Y. Hirose, H. Higuchi and T. Wada 1996 Seasonal abundance of Ooencyrtus nezarae Ishii (Hymenoptera: Encyrtidae), an egg parasitoid of phytophagus bugs, in summer soybean fields. Jap. J. Appl. Entomol. Zool., 40: 199204 (in Japanese with English summary)

Noda, T. 1993 Ovipositional strategy of Gryon japonicum (Hym: Scelionidae). Bull. Natl. Inst. Agro-Environ. Sci., 9: 1-51 (in Japanese with English summary)

Papaj, D. R. 2000 Ovarian dynamics and host use. Annu. Rev. Entomol., 45: 423-448

Price, P. W. 1973 Reproductive strategies in parasitoid wasps. Am. Nat., 107: 684-693

Price, P. W. 1974 Strategies for egg production. Evolution, 28 $76-84$

Quicke, D. L. J. 1997 Parasitic Wasps. Chapman \& Hall, London

Ratte, H. T. 1985 Temperature and insect development. In "Environmental Physiology and Biochemistry of Insects", ed. by K. H. Hoffmann, Springer, Berlin, pp. 33-66

Sagarra, L. A., C. Vincent, and R. K. Stewart 2000 Fecundity and survival of Anagyrus kamali Moursi (Hymenoptera: Encyrtidae) under different feeding and storage conditions. Eur. J. Entomol., 97: 177-181

Seal, D. R., P. A. Stansly and D. J. Schuster 2002 Influence of temperature and host on life history parameters of Catolaccus hunteri (Hymenoptera: Pteromalidae). Environ. Entomol., 31: $354-360$

Syme, P. D. 1975 The effects of flowers on the longevity and fecundity of two native parasites of the European pine shoot moth in Ontario. Environ. Entomol., 4: 337-346

Syme, P. D. 1977 Observations on the longevity and fecundity of Orgilus obscurator. Can. Entomol., 109: 995-1000

Takasu, K. and Y. Hirose 1985 Seasonal egg parasitism of phytophagous stink bugs in a soybean field in Fukuoka (In Japanese with English summary). Proc. Assoc. Plant. Prot. Kyushu, 31: 127-131

Takasu, K. and Y. Hirose 1986 Kudzu-vine community as a breeding site of Ooencyrtus nezarae Ishii (Hymenoptera: Encyrtidae), an egg parasitoid of bugs attacking soybean. Jap. J. Appl. Entomol. Zool., 30: 302-304 (in Japanese with English abstract)

Tingle, C. C. D. and M. J. W. Copland 1988 Predicting development of the mealybug parasitoids Anagyrus pseudococci, 
Leptomastis dactylopii and Leptomastidea arnornis under greenhouse condition. Entomol. Exp. Appl., 46: 19-21

Ueno, T. 1998 Adaptiveness of sex ratio control by the pupal parasitoid Itoplectis naranyae (Hymenoptera: Ichneumonidae) in response to host size. Evol. Ecol., 12: 643-654

Ueno, T. 1999a Host-feeding and acceptance by a parasitic wasp (Hymenoptera: Ichneumonidae) as influenced by egg load and experience in a patch. Evol. Ecol., 13: 33-44

Ueno, T. 1999b Adult size and reproduction in the ectoparasitoid wasp Agrothereutes lanceolatus Walker (Hymenoptera, Ichneumonidae). J. Appl. Entomol., 123: 357-362

Ueno, T. 1999c Host-feeding and reproduction in the parasitoid wasp Pimpla nipponica (Hymenoptera: Ichneumonidae).
Invert. Reprod. Develop., 35: 231-237

Ueno, T. and K. Ueno 2007 The effects of host-feeding on synovigenic egg development in an endoparasitic wasp, Itoplectis naranyae. J. Insect Sci., 7: 46. http://www.insectscience. $\operatorname{org} / 7.46 /$

van Lenteren, J. C., A. van Vianen, H. F. Gast, and A. Kortenhoff 1987 The parasite-host relationship between Encarsia formosa Gahan (Hym., Aphelinidae) and Trialeurodes vaporariorum (Westwood) (Hom., Aleyrodidae). XVI. Food effects on oogenesis, oviposition, life-span and fecundity of Encarsia formosa and other hymenopterous parasites. J. Appl. Entomol., 103: 69-84 